\title{
Internal heat gain from different light sources in the building lighting systems
}

\author{
Dariusz Suszanowicz, ${ }^{1, *}$ \\ ${ }^{1}$ University of Opole, Faculty of Natural Sciences and Technology, ul. R. Dmowskiego 7-9, 45-365 Opole, Poland
}

\begin{abstract}
EU directives and the Construction Law have for some time required investors to report the energy consumption of buildings, and this has indeed caused low energy consumption buildings to proliferate. Of particular interest, internal heat gains from installed lighting affect the final energy consumption for heating of both public and residential buildings. This article presents the results of analyses of the electricity consumption and the luminous flux and the heat flux emitted by different types of light sources used in buildings. Incandescent light, halogen, compact fluorescent bulbs, and LED bulbs from various manufacturers were individually placed in a closed and isolated chamber, and the parameters for their functioning under identical conditions were recorded. The heat flux emitted by $1 \mathrm{~W}$ nominal power of each light source was determined. Based on the study results, the empirical coefficients of heat emission and energy efficiency ratios for different types of lighting sources (dependent lamp power and the light output) were designated. In the heat balance of the building, the designated rates allow for precise determination of the internal heat gains coming from lighting systems using various light sources and also enable optimization of lighting systems of buildings that are used in different ways.
\end{abstract}

\section{Introduction}

Directive 2010/31/EU of the European Parliament and of the Council of 19 May 2010 on the energy performance of buildings [1] and the Construction Law of 7th July 1994 [2] require investors to prepare the energy performance of buildings. According to legislators, these acts will lead to an increase in the number of buildings with low energy requirements.

According to the energy performance of buildings preparation methodology, contained in the Minister of Infrastructure and Development Regulation of 27 February 2015 Pos. 376 [3], the annual need for nonrenewable primary energy for the integrated lighting system shall be determined for buildings and commercial premises. The methods of calculating energy requirements for an integrated lighting system presented in the Regulation do not apply, however, to residential buildings and premises.

In order to be able to design passive or "zero energy" residential buildings or to plan modernization of existing ones to the standards recommended for passive buildings, it is necessary to determine precisely the energy efficiency of lighting systems used in residential buildings.

For all types of buildings (including residential buildings), the energy performance of buildings preparation methodology assumes determining internal heat gains. However, no calculations concerning heat gain from lighting systems using different sources of light have been taken into consideration. Internal heat gains from

\footnotetext{
* Corresponding author: d.suszanowicz@uni.opole.pl
}

lighting affect the final energy consumption for heating public facilities as well as residential buildings $[4,5]$.

According to studies carried out by many researchers for various types of buildings, lighting accounts for 30\% of electricity consumption in office buildings [6], from 20 to $30 \%$ in hospitals [7], from 28 to $62 \%$ in school buildings [8], whereas in residential buildings it is approximately $12 \%[9,10]$. The results mentioned above show that the lighting systems in public facilities is particularly important for the energy efficiency of buildings.

The heat generated in the building's interior by the lighting system is heat gain during the heating season, while in the summer, when it is necessary to cool the rooms using air-conditioning systems, the heat from the lighting systems increases the demand for cooling in the building and thus has a negative effect on energy efficiency [11].

In order to calculate precisely the heat gains from building lighting, it is necessary to determine the energy parameters of the different light sources used in all types of buildings for which energy performance is prepared [12].

\section{Materials and methods}

The work analyses the consumption of electricity, luminous flux and heat flux emitted by various types of light sources most commonly used in buildings. A measuring stand was prepared, equipped with an insulated test chamber of $19 \mathrm{dm}^{3}$, in which different light sources 
were installed and the measuring instruments were connected. The diagram of the measurement station is shown in Fig. 1.

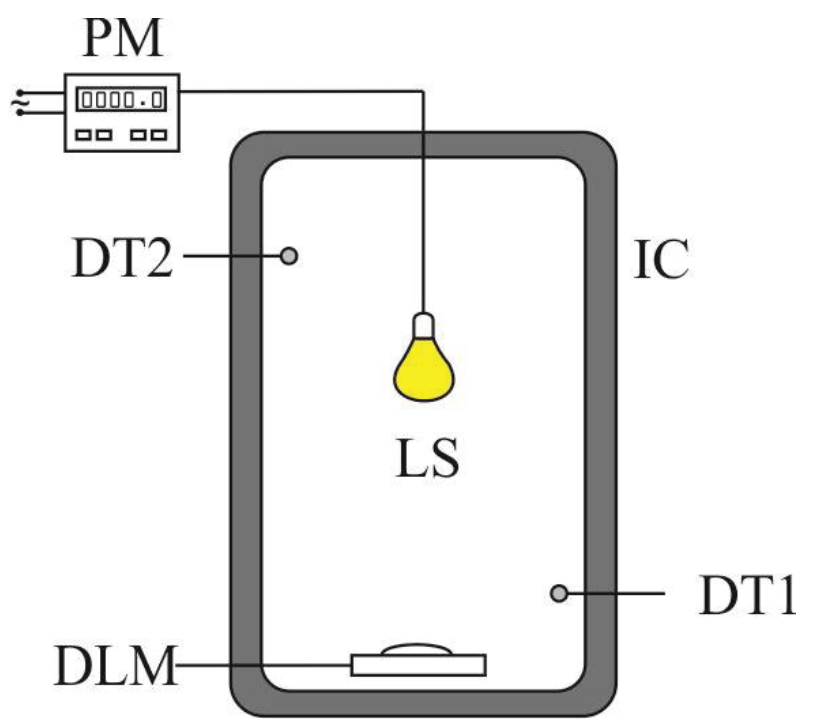

Fig. 1. Measurement station diagram: LS - light source, IC insulated chamber, PM - multifunctional electrical power meter, DT1, DT2 - digital thermometers, DLM - digital light meter.

In a closed, insulated chamber, different light sources were placed in turn: $100 \mathrm{Watt}$ incandescent light bulbs, 70 Watt halogen bulbs, 18 Watt compact fluorescent lamps and 12 Watt LED bulbs of different manufacturers with Edison E14 or E27 threads. The electricity consumption and the instantaneous power consumption were recorded using a multifunction electrical power meter. The temperature inside the measuring chamber was measured by two digital thermometers (one mounted at the top of the chamber, the other at the bottom), and the light emitted by the individual bulbs was registered using a digital light meter. The luminous flux emitted by a specific light source was recorded using a digital light meter.

All series of tests of the working parameters for individual light sources were started in identical environmental conditions (temperature inside and outside the chamber was $23^{\circ} \mathrm{C}$ ). After switching on the light source enclosed inside the insulated chamber, the changes in the air temperature inside the chamber, the power consumption of the source and the stream of light emitted by the light source were recorded.

In order to determine the required time of observation of the operating parameters of the analysed types of light sources, it was planned to observe the temperature changes of individual types of light bulbs by using a thermographic camera.

In order to record the heat radiation emitted by the examined light sources, the images of selected light sources in the infrared medium band were taken using a thermographic camera. Sample images showing the temperature of the LED, incandescent and compact fluorescent bulbs, after 3 minutes of their operation, are shown in Fig. 2.

As can be seen from the pictures shown in Fig. 2, the surface temperatures of the different types of light bulbs during their operation are significantly different from each other. After 3 minutes of operation, the LED bulb reached a temperature of $32.6^{\circ} \mathrm{C}$, a compact fluorescent lamp $-58.7^{\circ} \mathrm{C}$, while the filament temperature of an incandescent light bulb reached $216^{\circ} \mathrm{C}$ and the surface temperature of the bulb was $134^{\circ} \mathrm{C}$.

a)

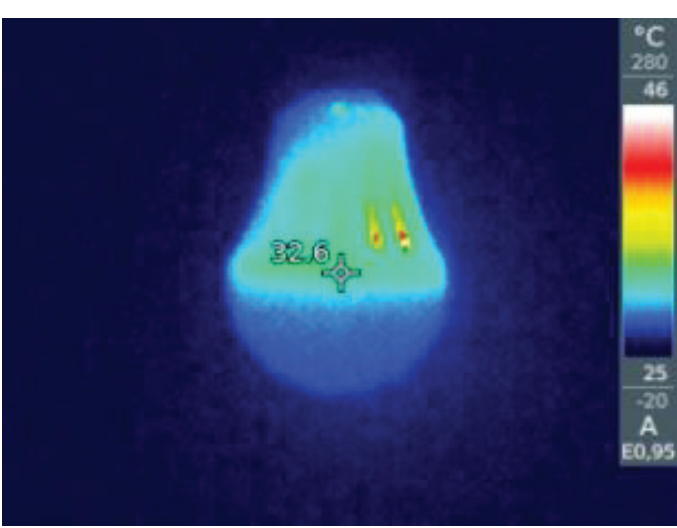

b)

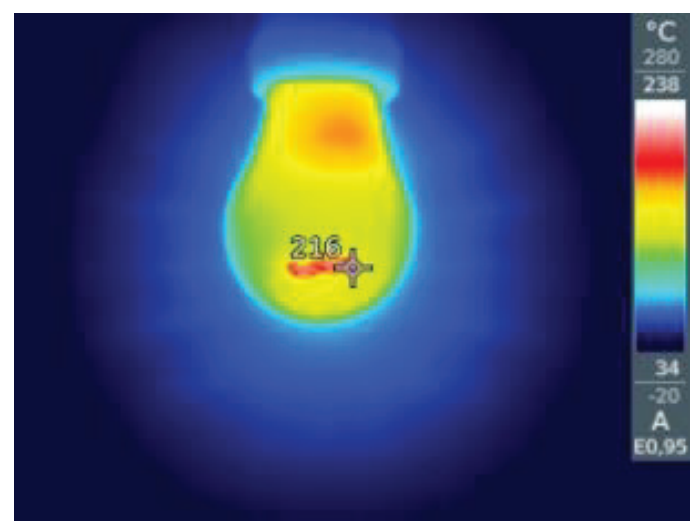

c)

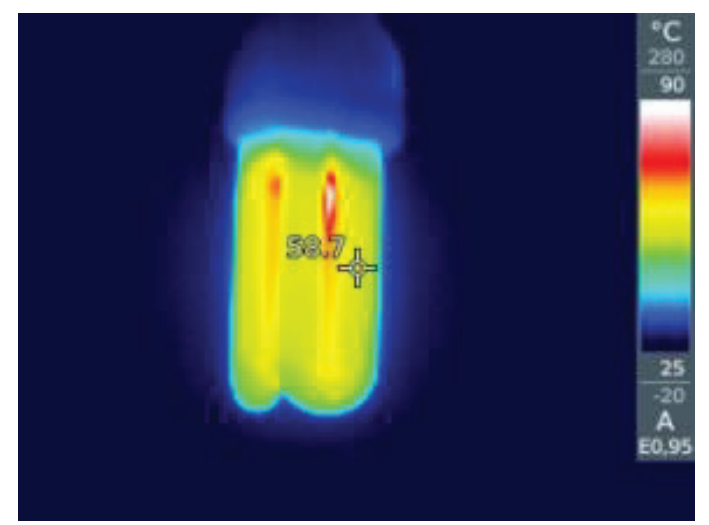

Fig. 2. Infrared images of the light sources: a) LED bulb, b) incandescent light bulb, c) compact fluorescent lamp.

Observations made by the thermographic camera allowed us to assume that the series of tests with the incandescent light source should last significantly shorter, so as not to overheat the bulb contained within a small insulated chamber from which the generated heat could not be discharged into the environment.

For each type of light source, bulbs of different manufacturers with the same nominal power values were tested by carrying five series of measurements and averaging the results. 


\section{Results and discussion}

Sample graphs of air temperature changes at two measuring points located in the lower and upper part of the chamber recorded during the study of different light sources are shown in Fig. 3.

a)

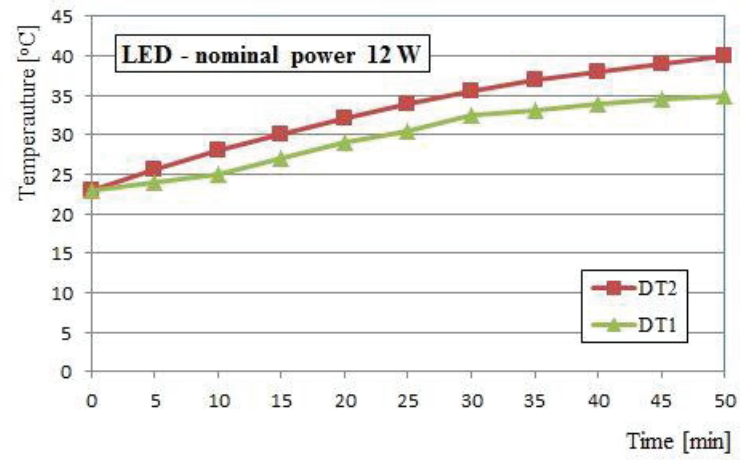

b)

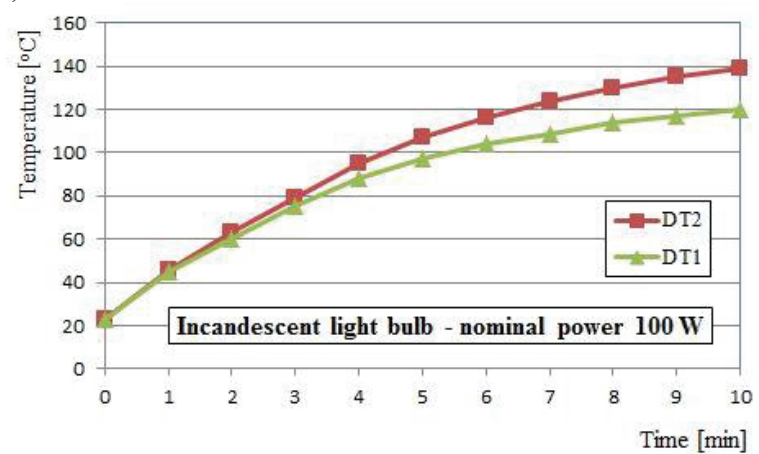

c)

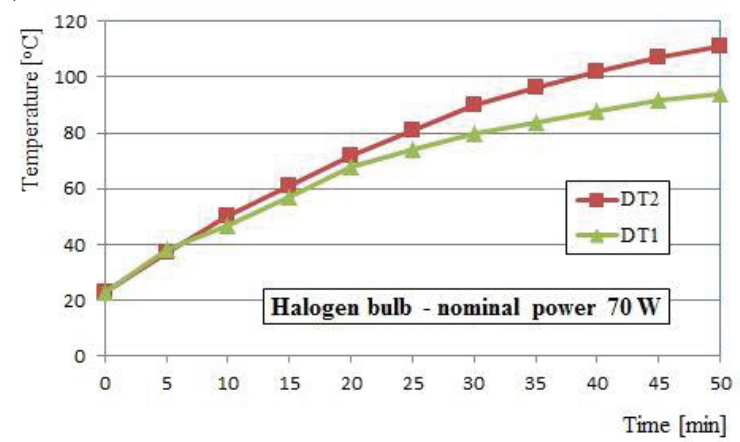

d)

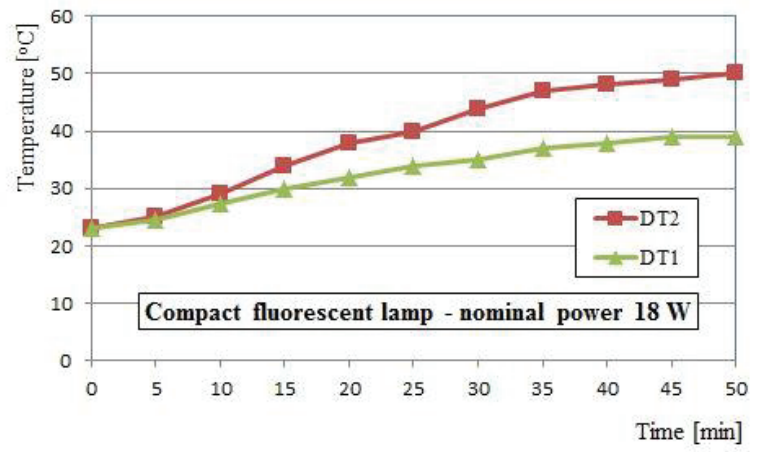

Fig. 3. Air temperature changes at two measuring points located in the lower (DT1) and upper (DT2) part of the chamber with the light sources: a) LED bulb, b) incandescent light bulb, c) halogen bulb, d) compact fluorescent lamp.
On the basis of the results obtained for the same light source across different series of measurements, we were able to determine the average temperature changes characteristic of the particular type of source.

Due to the thermal insulation of the test chamber walls, it was established that $100 \%$ of the heat emitted by the light source was consumed in order to heat the air inside the chamber.

Knowing the heat capacity of the air (dependant on the temperature inside the chamber) and the change of the average value of air temperature inside the chamber during the experiment, the heat output $\mathrm{P}_{\mathrm{h}}$ was determined for each measurement series, i.e. the heat transferred from the light source to the air inside the chamber during the experiment. The heat output was calculated on the basis of the formula (1):

$$
P_{h}=m \cdot c_{a} \cdot \Delta T \cdot t^{-1}[W]
$$

where:

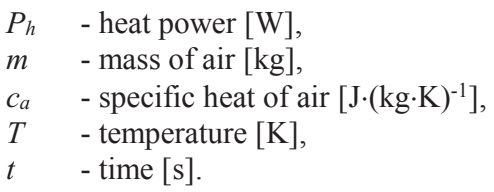

In all series of measurements, the electricity consumption of the light source was also recorded. The results of measurements of instantaneous energy consumption for incandescent bulbs, halogen bulbs, compact fluorescent lamps and LED bulbs, averaged in all series of measurements for particular source of light, were presented in Fig. 4.

The data collected from all series allowed us to establish, for each type of light source their actual electric power, which in the case of halogen bulbs and incandescent light bulbs was significantly higher (by $10 \%$ ) than their nominal power. On the other hand, the actual electric power of compact fluorescent lamps and LED bulbs was lower than nominally indicated by the manufacturers.

The research allowed us to determine, for each type of light source, the unit heat flux that is the empirical heat emission coefficient $\left(\mathrm{H}_{\mathrm{e}}\right)$, referenced to $1 \mathrm{~W}$ of the nominal light source.

If the value of the heat emission coefficient $\left(\mathrm{H}_{\mathrm{e}}\right)$ is 0 , the source does not emit any heat energy, and if it is 1 , it means that the source emits only heat. The heat emission coefficient $\left(\mathrm{H}_{\mathrm{e}}\right)$ is determined according to the formula (2):

$$
H_{e}=\frac{P_{h}}{P_{e}} \quad\left[\frac{W}{W}\right]
$$

where:

$P_{e} \quad$ - actual electrical power [W],

The $\mathrm{H}_{\mathrm{e}}$ coefficient will allows to determine quickly the internal heat gains from a building lighting system equipped with a particular type of light source. The unit of the heat emission factor $\mathrm{H}_{\mathrm{e}}$ is the $\mathrm{W}$ heat energy $/ \mathrm{W}$ electric energy. 
a)

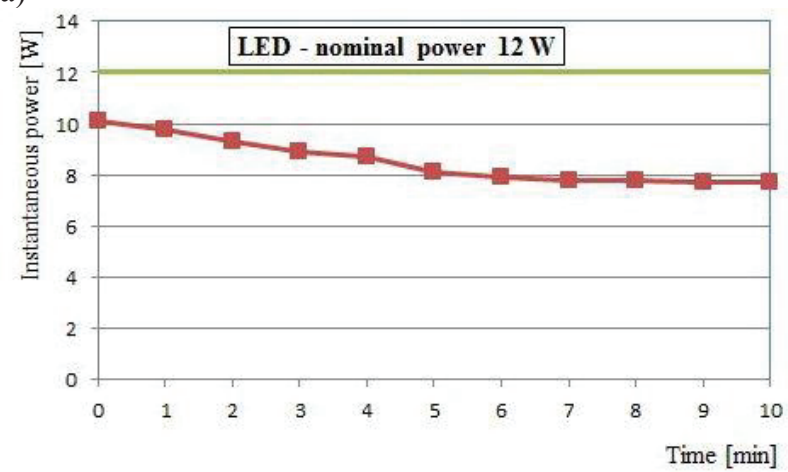

b)

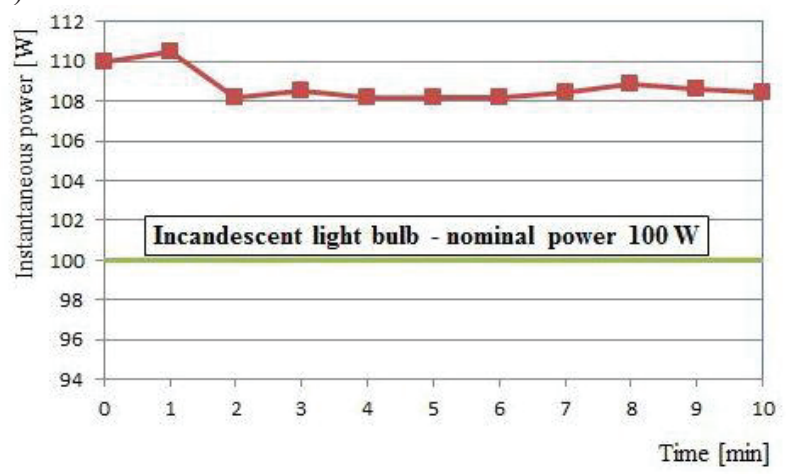

c)

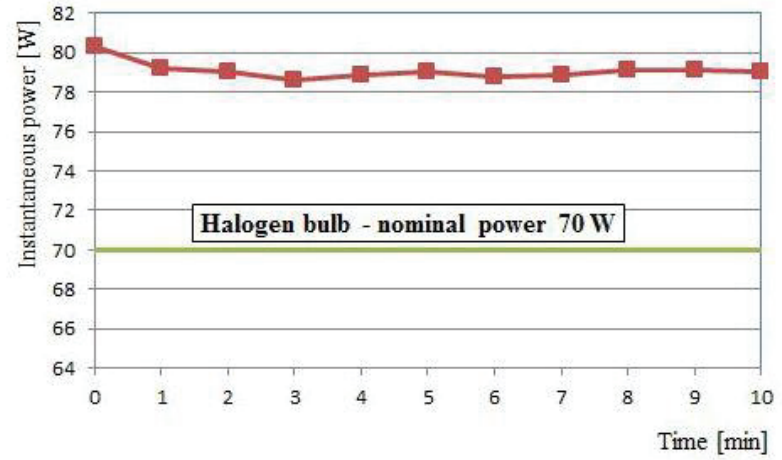

d)

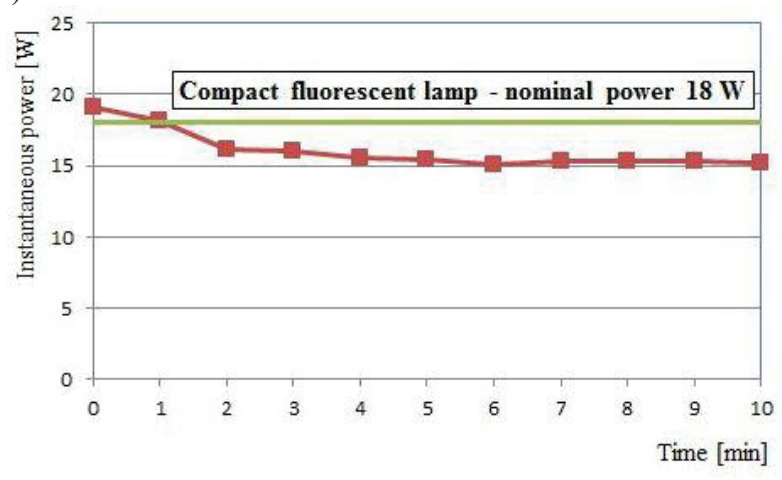

Fig. 4. Instantaneous power of the light sources: a) LED bulb, b) incandescent light bulb, c) halogen bulb, d) compact fluorescent lamp.

The luminous efficacy of each type of light source that is the quotient of the luminous flux emitted by the light source to the actual electric power $\left(\mathrm{P}_{\mathrm{e}}\right)$ taken from the source, was also determined. The unit of luminous efficacy is $1 \mathrm{~m} / \mathrm{W}$. The luminous flux and the actual electrical power recorded during the experiments were used to determine the average values for each light source. The determined values of luminous efficiencies enables us to compare the energy efficiency of different types of light sources.

The average values of the heat emission coefficient $\left(\mathrm{H}_{\mathrm{e}}\right)$ and the light efficiency determined for each light source during the analysis of test results are summarized in Table 1.

Table 1. Average values of the operating parameters of different light sources determined during the tests.

\begin{tabular}{|l|c|c|}
\hline \multicolumn{1}{|c|}{ Light sources } & $\begin{array}{c}\text { Heat emission } \\
\text { coefficient } \mathbf{H}_{\mathrm{e}},\end{array}$ & $\begin{array}{c}\text { Luminous } \\
\text { efficacy } \boldsymbol{\eta}, \mathbf{W} \\
\mathbf{I m} / \mathbf{W}\end{array}$ \\
\hline LED bulb & 0.08 & 140 \\
\hline $\begin{array}{l}\text { incandescent } \\
\text { light bulb }\end{array}$ & 0.95 & 12 \\
\hline halogen bulb & 0.82 & 16 \\
\hline $\begin{array}{l}\text { compact } \\
\text { fluorescent lamp }\end{array}$ & 0.31 & 56 \\
\hline
\end{tabular}

On the basis of experimental studies and analysis of the obtained results, we have proposed a correlation which enable us to determine the internal heat gains derived from lighting systems used in all types of buildings in the form of (3):

$$
Q_{H, o}=A_{f} \cdot E_{v} \cdot \eta^{-1} \cdot H_{e} \cdot t_{o}\left[\frac{k W h}{y r .}\right]
$$

where:

$Q_{H, o}$ - internal heat gain from lighting system [kWh/yr.],

$A_{f} \quad$ - floor area $\left[\mathrm{m}^{2}\right]$,

$E_{v} \quad$ - illuminance [lx],

$\eta \quad$ - luminous efficacy $[\mathrm{lm} / \mathrm{W}]$,

$H_{e} \quad$ - heat emission coefficient [W/W],

to - annual light system operating hours [kh/yr.].

When determining internal heat gains according to correlation (3), it is necessary to indicate the number of operating hours of the lighting system during the year $\left(t_{0}\right)$. Unfortunately, as far as residential buildings are concerned, it is very difficult to do such calculations therefore it was necessary to analyse the requirements and recommendations for lighting systems of such buildings.

On the basis of the Polish Standards [13, 14] and the recommendations included in the Minister of Infrastructure and Development Regulation on the energy performance of buildings preparation methodology or a part of a building and statement of energy performance of buildings [3], for different types of buildings the requirements concerning the average illuminance level of different types of premises and the number of lighting installation operating hours per year were developed and are summarized in Table 2. 
Table 2. Requirements for lighting systems of the selected building types.

\begin{tabular}{|l|c|c|}
\hline Building type & $\begin{array}{c}\text { Illuminance } \mathbf{E}_{\mathbf{v}}, \\
\mathbf{l x}\end{array}$ & $\begin{array}{c}\text { Annual light } \\
\text { system } \\
\text { operating hours } \\
\mathbf{t}\end{array}$ \\
\hline kh/yr. \\
\hline Residential & 250 & 1.8 \\
\hline Office & 500 & 2.5 \\
\hline Educational & 300 & 2.0 \\
\hline Service & 300 & 2.5 \\
\hline Store & 300 & 5.0 \\
\hline Hospital & 250 & 5.0 \\
\hline Production & 500 & 2.2 \\
\hline $\begin{array}{l}\text { Farm } \\
\text { (chickencoop) }\end{array}$ & 20 & 6.5 \\
\hline
\end{tabular}

The requirements for different types of light sources, as presented in Table 2, allow us to optimize the installed power of lighting sources in both residential and nonresidential buildings. Introducing the standard number of operating hours for a lighting system per year, enables us to compare the values of heat gains obtained from different buildings of the same type.

\section{Conclusions}

After reviewing the available literature on the subject and examining various light sources, a correlation was proposed to determine the internal heat gains $\mathrm{Q}_{\mathrm{H}, \mathrm{o}}$ from lighting systems used in all types of buildings. It should be emphasized that outside of the heating season, the heat from the building lighting systems influences the temperature rise inside the building and may cause the need for cooling by means of an air-conditioning system.

Based on the results obtained, the empirical heat emission factor $\mathrm{H}_{\mathrm{e}}$ was determined for the selected four types of lighting sources, depending on the power of the light source. The luminous efficacy $\eta$ of each type of light source, i.e. the ratio of the luminous flux emitted by the light source to the energy it consumes, was also determined.

The determined working parameters of different light sources will allow for accurate incorporation of internal heat gains from lighting systems using different light sources into the building's thermal balance, and will also allow to optimize lighting systems of different types of buildings.

As demonstrated by the conducted study, only in the case of LED light sources there is no higher nominal power consumption by the bulb during the first minutes after it has been switched on. Accordingly, it can be stated that only in the case of building lighting systems equipped with motion sensors and time switches it is recommended to use only LED light sources.

\section{References}

1. Directive 2010/31/EU of the European Parliament and of the Council of 19 May 2010 on the energy performance of buildings. Off. J. Eur. Union 18.6.2010 L 153 (2010)

2. Act of 7 July 1994 Construction Law. J. Laws pos. 290, 961, 1165, 1250 (2016)

3. Regulation Ministry of Infrastructure and Development on the methodology for determining the energy performance of a building or part of a building and energy performance certificates. $J$. Laws pos. 376 (2015)

4. K. Flodberg, Å. Blomsterberg, M.-C. Dubois, Int. J. Energy Environ. Eng. 3, 19 (2012)

5. E. Monstvilas, K. Banionis, V. Stankevičius, J. Karbauskaite, R. Bliūdžius, J. Civ. Eng. Manag. 16, $3(2010)$

6. R. Zmeureanu, C. Peragine, Energy Convers, Manage. 40, 1229-1236 (1999)

7. P. Torcellini, N. Long, S. Pless, R. Judkoff, Technical Report NREL/TP-550-34607, 1-115 (2005)

8. S. Chow, A.R. Ganji, B. 26th World Energy Engineering Congress, (Atlanta Georgia, 2003) DOI:10.1.1.576.5568

9. P. Bertoldi, B. Atanasiu, Proceedings of EEDAL'06 Conference, 267-272 (2006)

10. T. Crosbie, S. Guy, Int. J. Environ. Technol. Manage. 9, 220-235 (2008)

11. A. Byung-Lip, P. Ji-Woo, Y. Seunghwan, K. Jonghun, L. Seung-Bok, J. Cheol-Yong, Energies 8, 6658-6671 (2015)

12. K. Valančius, V. Lapinskienè, Environ. Eng. Conf. Proceedings, 31 (2014)

13. Polish Standard PN-EN 12464-1:2012, Light engineering (2012)

14. Polish Standard PN-EN 12665:2008, Light and lighting (2011) 